\title{
EUTANÁSIA, ORTOTANÁSIA E SUICÍDIO ASSISTIDO: A ÉTICA DO RESPEITO À DIGNIDADE E À AUTONOMIA DE PACIENTES EM ESTÁGIO TERMINAL ${ }^{1}$
}

\author{
EUTHANASIA, ORTHOTHANASIA AND ASSISTED SUICIDE: THE \\ ETHICS OF RESPECT FOR \\ THE DIGNITY AND AUTONOMY OF PATIENTS IN TERMINAL STAGE
}

\author{
MARCELO DE ARAÚJO \\ (UERJ / Brasil)
}

\begin{abstract}
RESUMO
Nos últimos anos a legislação brasileira que trata da proteção da dignidade e da autonomia de pacientes em estado terminal passou por importantes transformações. A nova legislação brasileira foi bem recebida por um amplo segmento da sociedade, incluindo-se aí a comunidade médica, a igreja católica, e jornalistas. A discussão em torno desse tema passou a ser articulada em torno do conceito de "ortotanásia". O objetivo deste artigo consiste em, por um lado, apresentar argumentos em favor do suicídio-assistido, uma prática atualmente proibida pela legislação brasileira, mas que seria, como se procura mostrar, coerente com os fundamentos morais da nova legislação brasileira. Por outro lado, procura-se mostrar também que o conceito de "ortotanásia" é inteiramente inadequado para uma discussão pública ampla desse tema, pois ele envolve, de modo implícito ou explícito, idéias teológicas e metafísicas que podem não ser compartilhadas por um amplo segmento da sociedade.
\end{abstract}

Palavras-chave: suicídio-assistido; eutanásia; dignidade; autonomia; direitos fundamentais

\begin{abstract}
Over the last few years the Brazilian legislation for terminally ill patients was changed in many respects. The new Brazilian legislation was welcome by different segments of society, including the medical community, the Catholic Church, and journalists. The public debate about this issue has been dominated by the concept of "orthothanasia". The aim of this article is to argue for assisted-suicide, a practice forbidden by law in Brazil, although it is coherent, as I intend to show, with the moral foundations of the new Brazilian legislation. On the other hand, I argue that the concept of "orthothanasia" is entirely inadequate for a broad, public discussion about this issue, for this concept implies, implicitly or explicitly, theological and metaphysical assumptions that may not be shared by a large segment of society.
\end{abstract}

Keywords: assisted-suicide; euthanasia; dignity; autonomy; basic rights 
"I am in life. I have already ended life. I want to exit life". ${ }^{3}$

Em 9 de agosto de 2012 o Conselho Federal de Medicina, através de resolução publicada no D.O.U., estabeleceu "diretivas antecipadas de vontade dos pacientes" para os casos de doença terminal, sem a perspectiva de cura. $\mathrm{O}$ documento afirma basicamente o seguinte:

\footnotetext{
"O Conselho Federal de Medicina [...]

Considerando a atual relevância da questão da autonomia do paciente no contexto da relação médico-paciente, bem como sua interface com as diretivas antecipadas de vontade;

$[\ldots]$

Considerando que os novos recursos tecnológicos permitem a adoção de medidas desproporcionais que prolongam o sofrimento do paciente em estado terminal, sem trazer beneficios, e que essas medidas podem ter sido antecipadamente rejeitadas pelo mesmo;

Considerando o decidido em reunião plenária de 9 de agosto de 2012, resolve:

Art. $1^{\circ}$ Definir diretivas antecipadas de vontade como o conjunto de desejos, prévia e expressamente manifestados pelo paciente, sobre cuidados e tratamentos que quer, ou não, receber no momento em que estiver incapacitado de expressar, livre $e$ autonomamente, sua vontade."
}

Essa resolução de 2012 está claramente em sintonia com uma resolução anterior, de 2006, que autoriza os médicos a suspenderam o tratamento, com a devida autorização prévia do paciente, nos casos de "enfermidades graves e incuráveis". A resolução de 2006, convém lembrar, havia sido anulada pelo Ministério Público Federal em 2007 sob a alegação de que ela era inconstitucional. Em 2010, porém, ela foi novamente tornada válida, após a revogação da liminar que a anulava. O caput da resolução de 2006 afirma o seguinte:

\footnotetext{
"Na fase terminal de enfermidades graves e incuráveis é permitido ao médico limitar ou suspender procedimentos e tratamentos que prolonguem a vida do doente, garantindo-lhe os cuidados necessários para aliviar os sintomas que levam ao sofrimento, na perspectiva de uma assistência integral, respeitada a vontade do paciente ou de seu representante legal.",
}

É importante notarmos que tanto a resolução de 2006 quanto a de 2012 não se deram de modo isolado de um debate bem mais amplo e que vem ocorrendo em vários outros países. Com efeito, resoluções semelhantes já foram implementadas, ou vêm sendo discutidas, em países como, por exemplo, Estados Unidos, Suíça, Bélgica, e Holanda.

O estado americano do Oregon aprovou de modo pioneiro em 1998 uma medida que, tal como a recente resolução brasileira, visa minimizar o sofrimento de pacientes em "fase terminal ethic@-Florianópolis v.12, n. 1, p.15-24,Jun. 2013. 
de enfermidades graves e incuráveis". Em Washington, essa aprovação ocorreu mais recentemente, em 2009; e em novembro de 2012 os residentes do estado americano de Massachusetts foram conclamados a se manifestar sobre essa questão, tendo decidido nas urnas pela não aprovação das medidas que já haviam sido incorporadas à legislação do Oregon e à de Washington. Essa questão vem sendo debatida nos Estados Unidos sob a designação de "Death with Dignity Act".

No entanto, o texto relativo à votação que se deu em novembro de 2012 nos Estados Unidos era bastante diferente do texto da resolução brasileira no que concerne a um aspecto fundamental. Os dois textos diferem no modo como compreendem o que significa proporcionar ao paciente em fase terminal uma morte digna. O problema que me interessa examinar aqui diz respeito à questão sobre até que ponto as resoluções brasileiras de 2006 e 2012, apesar de representarem o que considero um claro avanço na legislação brasileira, são realmente coerentes com os fins a que se propõem. O que eu gostaria de sugerir é que a legislação americana, nos estados em que foi aprovada, parece ser bem mais coerente com o ideal de respeito à autonomia $\mathrm{e}$ à dignidade dos pacientes do que a nova legislação brasileira.

Enquanto a nova legislação brasileira diz respeito à suspensão dos tratamentos que prolongam a vida de um paciente nas ocasiões em que o paciente não deseja mais o tratamento, e não há real expectativa de cura, a legislação americana dos estados do Oregon e Washington diz respeito não apenas à suspensão do tratamento, mas à possibilidade de o médico poder prescrever ao paciente uma substância que, administrada pelo próprio paciente, e não pelo médico ou qualquer outra pessoa, induzirá à sua morte. O que está em questão na legislação americana, portanto, é a possibilidade do "suicídio assistido", ainda que a expressão "suicídio assistido" nem sempre seja usada nesse contexto. (Às vezes se fala alternativamente em "physician-assisted dying" ou "aid-in-dying"). ${ }^{6}$ A petição por traz da votação que se deu em novembro de 2012 nos Estados Unidos, e que foi rejeitada por uma margem de apenas dois por cento de diferença ${ }^{7}$, é explícita nesse ponto. $\mathrm{O}$ que se propunha é que o paciente "...suffering from a terminal disease that will cause death within six months may obtain medication that the patient may self administer to end his or her life in a humane and dignified manner."

A legislação brasileira, por outro lado, evidentemente, não permite o suicídio assistido, i.e. um procedimento que permita ao médico informar e garantir ao paciente o acesso a algum tipo de substância que induza à sua morte. O que a legislação brasileira permite agora é a 
suspensão do tratamento de modo a, como diz o texto de 2012, evitar "medidas desproporcionais que prolongam o sofrimento do paciente em estado terminal"; ou, como diz o texto de 2006, implementar medidas "para aliviar os sintomas que levam ao sofrimento, na perspectiva de uma assistência integral."

Contudo, uma vez que tenhamos reconhecido que o respeito à autonomia e à dignidade da pessoa humana torna legítima a suspensão do tratamento nos casos em que o próprio paciente deseja de modo expresso e refletido a suspensão de um tratamento que apenas prolonga o seu sofrimento, sem a real perspectiva de cura, por que então deveríamos negar ao paciente isso que a legislação americana já permite em alguns estados, i.e. que o paciente possa, ele próprio, provocar a sua morte? Em um artigo recentemente publicado no The New York Review of Books, em 8 de outubro de 2012, Marcia Angell chama atenção para um argumento que, a meu ver, torna claro por que a simples suspensão do tratamento pode não ser a melhor medida para fazermos jus à dignidade e autonomia do paciente em estágio terminal, sobretudo ao termos em mente a "perspectiva de uma assistência integral”, que é explicitamente salientada pela resolução brasileira de 2012:

\begin{abstract}
But the right to refuse life-sustaining treatment presupposes that there is such a treatment to refuse. Suppose there isn't. Many dying patients might not be receiving such treatment because they can live without it. For example, although some patients with widespread lung cancer might need a mechanical ventilator to survive, patients with widespread cancer of the pancreas, which can also inflict terrible suffering, might not need that or any other treatment to remain alive while they slowly die in great misery. Shouldn't they have the same right to hasten their deaths?'
\end{abstract}

O argumento é claro: em algumas circunstâncias o sofrimento do paciente não será aliviado pela mera suspensão do tratamento porque não há, rigorosamente falando, um tratamento a ser suspenso. A legislação brasileira, portanto, não é realmente capaz de levar às últimas consequências a "perspectiva de uma assistência integral", pois ela trata de modo diferenciado o paciente que, por paradoxal e cruel que possa parecer, tem a "sorte" de estar sendo mantido vivo por algum tipo de aparelho cujo funcionamento pode ser a qualquer momento interrompido, caso o paciente assim o deseje. O paciente que, por outro lado, estiver vivendo sob o tormento de um sofrimento igualmente intenso, e sem a perspectiva de cura, mas que, por paradoxal e cruel que possa parecer, não tem a "sorte" de estar sendo mantido vivo por força de um tratamento que pudesse ser interrompido, caso ele ou ela assim o desejasse, não poderá ser beneficiado pela nova 
legislação brasileira. Considerada nesses termos, a resolução brasileira me parece injusta, pois ela não trata de modo igual pacientes de "enfermidades graves e incuráveis" em igual situação de sofrimento.

No entanto, contra esse argumento, alguém poderia alegar que o que está em questão no primeiro caso é a realização de uma "ortotanásia", por oposição à "eutanásia passiva", ou "suicídio assistido", que ocorreria no segundo caso, caso fossem proporcionados ao paciente os meios para, ele próprio, provocar a sua morte. Mas essa distinção entre, de um lado, "ortotanásia" e, de outro lado, "eutanásia passiva" ou "suicídio assistido" é realmente cabível? Parece-me que não. O conceito de "ortotanásia" envolve premissas teológicas e metafísicas que, a meu ver, deveriam ser deixadas de lado no âmbito de um debate sobre a implementação de medidas que terão reflexo sobre a vida (e o fim da vida) de pessoas que, eventualmente, possam não compartilhar as mesmas crenças teológicas e metafísicas das pessoas que acreditam que haja aqui uma distinção relevante. Gostaria de explicar melhor esse ponto.

A ideia de "ortotanásia", tanto em 2006 como também mais recentemente em 2012, foi amplamente divulgada pela imprensa brasileira como sendo essencialmente diferente da eutanásia passiva ou do suicídio assistido. ${ }^{10} \mathrm{~A}$ prática da ortotanásia, por oposição à eutanásia passiva ou ao suicídio assistido foi endossada, inclusive, por alguns segmentos da igreja católica no Brasil. O que se alega é basicamente o seguinte: o médico que, com a autorização expressa e esclarecida do paciente, interrompe o tratamento não está fazendo nada "ativamente". Ele estaria apenas deixando que a vida seguisse naturalmente seu rumo. A morte, assim, seria concebida como parte de um processo natural. Prolongar artificialmente a vida significaria proceder de modo contrário aos desígnios da natureza. Dessa forma, não estaria aqui em questão uma forma de "eutanásia passiva" ou de "suicídio assistido", mas de "ortotanásia". O prefixo "orto", nesse neologismo que parece ter sido empregue pela primeira vez pelo jesuíta Javier Gafo, designaria a morte "correta", em harmonia com os ciclos naturais da vida. ${ }^{11}$ Ao conceito de ortotanásia subjaz, portanto, a ideia teológica ou metafísica segundo a qual haveria uma hora "correta" para morrer, um momento determinado, não pelo próprio paciente ou por quem quer seja, mas pelo curso inexorável da natureza. Essa ideia, porém, me parece equivocada.

Imaginemos um paciente que, aos 104 anos de idade, leva uma vida mantida por aparelhos e que isso the causa bastante sofrimento. Imaginemos também que ele ou ela, ainda assim, não tenha dado seu assentimento para o desligamento dos aparelhos. Enquanto a 
tecnologia à sua disposição permitir, esse paciente deseja permanecer vivo. Se interrogado por que deseja continuar vivo - supondo, aliás, que alguém tenha seriamente o direito de lhe perguntar isso - o paciente poderia alegar uma diversidade de razões. A despeito de todo sofrimento, ele ou ela poderia querer continuar vivendo, por exemplo, porque deseja estar em condições de conhecer seu primeiro trineto, ainda nos primeiros meses de gestação. Alternativamente, o paciente poderia alegar desejar assistir à próxima Copa do Mundo, pela primeira vez sediada no Rio de Janeiro do século XXI, ainda que a televisão a partir da qual assistirá aos jogos tenha de ser posicionada ao lado de uma parafernália de equipamentos e fármacos que prolongam sua vida. É bastante razoável supor que, se o curso inexorável da natureza não tivesse sido perturbado por esse arsenal tecnológico, esse paciente já teria morrido de causas naturais há muito tempo.

Se o conceito de "ortotanásia" tivesse, de fato, algum sentido normativo, poderíamos legitimamente dizer para esse paciente que ele está fazendo algo de errado, pois, afinal, a hora dele já teria chegado há muito tempo. O desejo de prolongar indefinidamente sua própria vida, de um modo artificial como esse, estaria em conflito com o curso regular da natureza. Mas a questão é sabermos se poderíamos legitimamente fazer uma tal alegação diante desse paciente. Parece-me que não. Com efeito, os mesmos princípios relativos à dignidade e à autonomia da pessoa humana, que garantem ao paciente em fase terminal a remoção de aparelhos, nas circunstâncias em que o próprio paciente julga que sua vida não vale mais a pena ser vivida, devem garantir também ao paciente de 104 anos que quer assistir à próxima Copa do Mundo, ou conhecer o seu primeiro trineto, a preservação de sua vida. A introdução da ideia de ortotanásia como um conceito normativo no segundo caso constituiria uma razão não justificada para a realização de um assassinato. Ora, mas se isso é assim, por que seria então lícito invocar a ideia de “ortotanásia” em um caso, mas rejeitá-la no outro?

A meu ver, não há nada de intrinsecamente equivocado com a suposição de que haja algo como um "ciclo natural da vida", um ciclo que inevitavelmente envolveria nascimento, vida, e morte. O problema, porém, é que os defensores da ideia de "ortotanásia" concebem esse ciclo natural da vida em termos normativos: a vida que segue seu curso natural, e que não é indefinidamente prolongada por aparelhos, seria mais certa ou mais digna do que a vida prolongada artificialmente. Esse argumento propõe, portanto, que há boas razões para aprovarmos a suspensão de tratamento nos casos de pacientes terminais, mas nega, por outro 
lado, que o ciclo natural da vida possa ser ativamente abreviado por quem quer seja, mesmo pelo próprio paciente. Dessa forma, esse mesmo argumento nega também que qualquer pessoa possa ter o direito de auxiliar um paciente a dar fim à sua própria vida. Em entrevista recentemente publicada no site do Conselho Federal de Medicina em 24 de setembro de 2012, Dom Raymundo Damasceno Assis, atual presidente da Conferência Nacional dos Bispos do Brasil (CNBB), afirma o seguinte:

\footnotetext{
A intuição de Pio XII e que foi sendo aprofundada com João Paulo II, sem dúvida, é muito importante, enquanto opõe-se claramente à prática da eutanásia, e prevê que não se deve praticar a chamada distanásia, ou seja, o prolongamento do processo do morrer.

$[\ldots]$

Entende-se por ortotanásia como a morte no tempo e momento "certos", sem abreviações de um lado (que seria eutanásia) e muito menos intervenções inúteis e fúteis que somente prolongam o processo do morrer (que é a obstinação terapêutica ou distanásia). Entre os dois extremos, deixar a natureza seguir seu curso natural. ${ }^{12}$
}

A consequência desse argumento, no entanto, é que ele nega, implícita ou explicitamente, que o hipotético paciente de 104 anos, a que me referi acima, leve uma vida digna. Se o que é relevante para a aprovação da ortotanásia, e rejeição da eutanásia passiva ou do suicídio assistido, é que a vida digna chegue ao seu termo em consonância com o ciclo natural da vida, o paciente de 104 anos, que obstinadamente insiste em permanecer vivo graças ao auxílio de aparelhos, e a despeito de grande dor, deve estar, segundo a perspectiva dos teóricos da ortotanásia, fazendo algo de errado. O presidente da CNBB afirma explicitamente, inclusive, no trecho da entrevista citada acima, que "não se deve praticar a chamada distanásia, ou seja, o prolongamento do processo do morrer." O que o presidente da CNBB diria para o hipotético paciente de 104 anos eu não sei.

Essa estipulação prévia acerca do que conta, e do que não conta, como uma vida realmente digna de ser vivida me parece extramente equivocada no âmbito de uma discussão ampla sobre medidas jurídicas que afetam a vida (e o fim da vida) de pessoas que possam não compartilhar as teses teológicas e metafísicas subjacentes ao conceito de ortotanásia. A decisão sobre se a vida do hipotético paciente de 104 anos é ou não digna de ser vivida envolve necessariamente uma consideração sobre o modo como o próprio paciente concebe o valor de sua vida. Cabe em última instância ao próprio paciente decidir se o valor de sua vida está ou não 
subordinado a considerações metafísicas e religiosas sobre os ciclos naturais da vida; se está subordinado ao cultivo de laços familiares que o levam a querer viver o suficiente para ver o seu primeiro trineto nascer; ou mesmo se está subordinado a considerações aparentemente menos nobres em torno da expectativa de poder ver o seu país sediar (e talvez vencer) a próxima Copa do Mundo. Com relação a esse ponto James Griffin afirma, a meu ver de modo bastante acertado, o seguinte: "What we attach value to, what we regard as giving dignity to human life, is our capacity to reflect on, to choose, and to pursue what we ourselves decide is a good life." (p. 319). ${ }^{13}$ Não são, portanto, apenas considerações sobre os ciclos naturais da vida os únicos parâmetros a partir dos quais podemos considerar o valor de uma vida. Na verdade, a partir mesmo do momento em que julgamos relevante, por exemplo, nos submetermos a procedimentos médicos rotineiros como a aplicação de vacinas, nós já estamos interferindo no curso natural da vida, pois é evidente que sem a intervenção de vacinas, e outras medidas similares, teríamos, de modo geral, uma expectativa de vida bem inferior àquela que teríamos se permitíssemos que a vida seguisse por si só seu curso "natural". ${ }^{14}$

O conceito de "ortotanásia” tem, a meu ver, na melhor das hipóteses, uma função retórica, e não é de se estranhar que, no debate internacional, sobretudo em língua inglesa, esse termo, ou algum correlato seu, seja praticamente inexistente. O termo tem uma função retórica porque permitiu a introdução de um debate que levou a importantes avanços na legislação brasileira, sem que, porém, tenham sido claramente trazidas para a discussão no âmbito do debate público ideias mais controversas como, por exemplo, a eutanásia passiva ou o suicídio assistido. A possibilidade de suspensão consentida do tratamento que mantém vivo um paciente em fase terminal, aliada à aprovação do suicídio assistido, nos termos em que ele foi implementado, por exemplo, em alguns estados americanos, constituem a meu ver práticas que promoveriam o respeito à dignidade e autonomia do paciente de forma mais integral. A legalização de apenas uma dessas práticas pode representar uma restrição da autonomia do paciente e uma violação de sua dignidade. 


\section{Notas}

${ }^{1}$ Este artigo contou com apoio financeiro do CNPq. Ele foi inicialmente discutido no "IV Congresso de Bioética do Rio de Janeiro", realizado na Universidade do Estado do Rio de Janeiro em outubro de 2012, e no simpósio "Religião e Política: A Secularização no Brasil”, realizado na PUC-Porto Alegre, em dezembro de 2012. Aos participantes de ambos os eventos agradeço pelas questões, críticas, e segestões.

${ }^{2}$ Universidade do Estado do Rio de Janeiro, Universidade Federal do Rio de Janeiro, Pesquisador do CNPq, Alexander von Humboldt-Fellow.

${ }^{3}$ Depoimento de paciente terminal retratado no documentário How to die in Oregon, por Peter Richardson, 2011; a frase ocorre aproximadamente aos 09:00 do filme. Outro importante documentário sobre a questão do suicídio assistido é Terry Pratchett: Choosing to Die, por BBC Two, 2011.

${ }^{4}$ DIÁRIO OFICIAL DA UNIÃO: “RESOLUÇÃO No- 1.995, DE 9 DE AGOSTO DE 2012”, p. 269-270. (Grifos meus).

${ }^{5}$ DIÁRIO OFICIAL DA UNIÃO: “RESOLUÇÃO No- 1.805, DE 9 DE NOVEMBRO DE 2006”, p. 169. (Grifos meus).

${ }^{6}$ Cf. Marcia ANGELL: "May Doctors Help You to Die?". In: The New York Review of Books, 8 de outubro de 2012.

7 Cf. BOSTON.COM (2012): http://www.boston.com/news/special/politics/2012/general/mass-ballot-question-2election-results-2012.html

${ }^{8}$ Cf. Massachusetts Initiative Petition (2011-2012):

http://www.consciencelaws.org/laws-proposed/usa/masschusetts01.htm (acessado em 25 de novembro de 2012).

${ }^{9}$ Marcia ANGELL, op. cit.

${ }^{10}$ O ESTADO DE S. PAULO: "Igreja apóia permissão para desligar aparelhos de pacientes terminais. Advogados pedem cautela com nova norma médica, que dá ao doente direito de optar por morrer naturalmente”, 11 de novembro de 2006. Cf. também O ESTADO DE S. PAULO: "Justiça Federal derruba liminar e libera prática da ortotanásia no País", 4 de dezembro de 2010, disponível em: http://www.estadao.com.br/noticias/impresso,justicafederal-derruba-liminar-e-libera-pratica-da-ortotanasia-no-pais,649301,0.htm Cf. também VIDA E ÉTICA: "Ortotanásia: o poder de aliviar o sofrimento de pacientes terminais", ano 2, n. 5, 2011, p. 14-16 (Publicação do CREMEB - Conselho de Medicina do Estado da Bahia).

${ }^{11}$ GAFO, Javier. 1990. "La eutanasia y la ética del bienmorir”. Revista Médica del Uruguay, vol. 6, p. 95-102.

${ }^{12}$ CONSELHO FEDERAL DE MEDICINA: "Entrevista ao CFM: CNBB apoia ortotanásia”, 24 de Setembro de 2012 (grifos meus). Disponível em:

http://portal.cfm.org.br/index.php?option=com_content\&view=article\&id=23257:entrevista-ao-cfm-cnbb-apoiaortotanasia\&catid=3 (acessado em 31 de outubro de 2012).

${ }^{13}$ James GRIFFIN: "First steps in an account of human rights". European Journal of Philosophy, vol. 9, 2001, 306327.

${ }^{14}$ Agradeço a Rodrigo Siqueira Batista pela alusão a esse argumento sobre o modo como a aplicação de vacinas, por si só, já representa uma interferência no curso "natural” da vida.

ethic@-Florianópolis v.12,n.1,p.15-24,Jun.2013. 


\section{Bibliografia}

ANGELL, Marcia. "May Doctors Help You to Die?" In: The New York Review of Books, 8 de outubro de 2012.

BRASIL. Diário oficial da União. Resolução $n^{\circ}$ 1.995. 9 de agosto de 2012, p. 269-270.

—. Resolução $n^{\circ}$ 1.805. 9 de novembro de 2006, p. 169.

CONSELHO FEDERAL DE MEDICINA. Entrevista ao CFM: CNBB apoia ortotanásia.

Disponível em:

http://portal.cfm.org.br/index.php?option $=$ com_content\&view $=$ article\&id=23257:entrevista-aocfm-cnbb-apoia-ortotanasia\&catid=3. Acesso em 31 de outubro de 2012.

GAFO, Javier. "La eutanasia y la ética del bienmorir". Revista Médica del Uruguay, vol. 6, 1990, p. 95-102.

GRIFFIN, James. "First steps in an account of human rights" In: European Journal of Philosophy, vol. 9, 2001, p. 306-327.

MASSACHUSETTS INITIATIVE PETITION (2011-2012). Diaponível em:

http://www.consciencelaws.org/laws-proposed/usa/masschusetts01.htm Acesso em: 25 de novembro de 2012.

RICHARDSON. Peter. How to die in Oregon. [Documentário] Produção e direção de Peter Richardson. Estados Unidos, 2011. 107 minutos. 